\title{
CONSTRUCTIVE FEATURES OF DEVICE TO REMOVE APICAL SHOOTS OF POTATOES
}

\author{
Aleksandr Levshin, Irina Gasparyan, Boris Bitsoev, Sergey Shchigolev \\ Russian Timiryazev State Agrarian University, Russia \\ alev200151@ rambler.ru, irina150170@yandex.ru, bicoev_boris@mail.ru, sergeysch127@mail.ru
}

\begin{abstract}
The article presents new design solutions used to remove the apical shoots of potatoes in order to increase the photosynthetic activity of plants due to the development of lateral shoots and increase the total leaf surface. Removal of plant tops on potatoes is carried out in the period of $14 \ldots 20$ days after germination. This leads to an increase in the yield on different varieties by about 6.6-16.3\% compared to the control (variety Luck $16.3 \%$, variety: Red Scarlet is $9.2 \%$, grade Aurora $6.6 \%$ ). A mechanized device for removing potato plant tops has been developed. Therefore, the justification of the parameters and modes of operation is important and relevant to ensure quality removal of potato tops. The incision should be clear without any breakdowns, as the damage through which pathogens can penetrate, especially viral diseases that are transmitted by contact, increases. The calculations allowed to establish the correct shape of the cutting knife, their number, as well as the cut angle of the cutting disc, which allows you to perform a quality cut. The data obtained allow us to conclude that to ensure high-quality and reliable cutting of potato shoots during decapitation, a cutting rotor with three knives should be used, rotating at a frequency of $1200 \mathrm{~min}^{-1}$, having an external diameter of the cutting edges of at least $0.35 \mathrm{~m}$, the length blade with the specified rotor parameters will be about $0.04 \mathrm{~m}$.
\end{abstract}

Keywords: removal of tops, cut without support, cutting edge, speed of the unit.

\section{Introduction}

The cultivation of clean ecological products is currently relevant. In cultivation technologies it is possible to use technological methods that allow increasing the crop yield using the biological potential of a plant. Genetically, potatoes can produce high yields. In many countries, the yield is quite high, reaching up to $100.0 \mathrm{t} \cdot \mathrm{ha}^{-1}$, for example, in Eastern Europe, despite the short growing season, the yield reaches $60.0-80.0 \mathrm{t} \cdot \mathrm{ha}^{-1}$ and higher [1]. Some researchers attribute the yield to the amount of absorbed solar radiation [2]. Creating a larger leaf area and long-term preservation of leaf mass contributes to an increase in the crop yield.

The coordinated development of plants is the interaction of growth hormones. One of such interactions is inhibition of lateral buds by the growing apical bud (apical dominance). When the apical bud is removed or the growing end shoot is cut, the hindered side buds start to grow and form the side shoots on which the leaves develop and thus the photosynthetic surface of the plant increases. This technique has been used in agriculture for a long time, for example, tomatoes are formed in protected ground or by cutting the habit of fruit trees in fruit growing, they are used to produce larger tulip bulbs, for seed output in hemp breeding, etc. [3-7]. Also works are known on potatoes [8-11]. Removal of the apical bud was carried out manually. A device for decapitation of potatoes (UDC) was developed for mechanized processing. The cut of the apical shoot must be carried out qualitatively, since this damage may contribute to introduction of various pathogens, especially viral, transmitted by contact. Therefore, for high-quality cutting of the tops of potato plants it is important to choose the correct parameters and modes of operation of the cutting apparatus.

The purpose of the research is to substantiate the method of calculating the rotary cutting apparatus for an irrelevant cut in a device for removing the tops of potato stalks.

\section{Material and methods}

A device for decapitation of potatoes [11] consists of a pneumatic system, cutting apparatus and a disinfectant system, Fig. 1. The device moves along the rut between the rows of potatoes. Potato bushes are in front of the machine. The optimal dates for decapitation of potatoes are 14-20 days after germination [12]. During this period the shoots of potato have a compact size. The stems are straight and juicy, directed upwards. The shoots are grouped around the tuber.

The shrubs of potato fall into the casing of the leaflet and are lifted by the air flow, forming a vertical bundle (the bush has some of dead shoots, and also the shoots can be easily deflected). The disinfecting system treats the cutting apparatus (rotary discs) by any means (potassium permanganate, hydrogen peroxide, etc.) to prevent from infection by various pathogens, especially viral diseases, 
since many of them are transmitted by contact. The injuries quickly heal. The solution from the treated discs is applied to the place of cutting the shoots of potatoes. During the turning of the rotary discs, the stems are cut with sterile knives 1.0-1.5 cm from the top of the plant. The important point is correct selection of the cutting apparatus, its size and modes of operation.

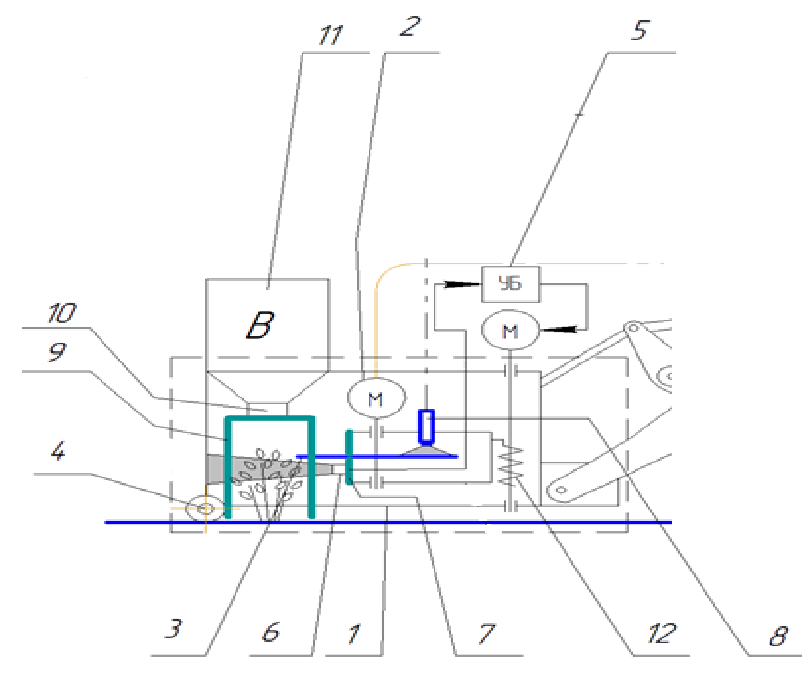

Fig. 1. Device for decapitation of potatoes: 1 - frame; 2 - hydraulic motor; 3 - cutting disc; 4 - rollers; 5 - control unit; 6 - optical sensor; 7 - casing; 8 - nozzle; 9 - air intake; 10 - duct; 11 - fan; 12 - control mechanism

\section{Research results}

The use of technological methods - removal of the apical kidney (decapitation) allows using the whole genetic potential of a plant without increasing the use of fertilizers and other agrochemicals.

Removal of the apical bud increases the total leaf surface of the plant due to the formation of new leaves from the lateral buds. Also more organic matter is producing and the yields are increasing. According to a number of authors [12], the yield increase without additional costs for fertilizer is 6.6$16.3 \%$, depending on the variety. Thus, the Luck variety reacts to decapitation by increasing the yield by $16.3 \%$ regardless of the climatic year, the Red Scarlet variety increases the yield by $9.2 \%$, and the Aurora variety by $6.6 \%$.

While decapitation is carried out, the stems are erect, juicy, directed upwards, have a compact appearance, because they are grouped around the tuber.

The important point is the quality of the cut, the cut must be clear without the mess, since there is increased damage through which pathogens can penetrate, especially viral diseases that are transmitted by contact. Therefore, the quality of the cut will depend on the choice of the cut height, the size of the cutting rotor and its modes of operation. The cutting machine must meet the following conditions:

- steady cut of plants on all operating modes;

- work in all range of working speeds of the car without passes of stalks.

It is proposed to use a rotary-disk cutting apparatus with fixed knives to cut the upper part of the stems in the device under consideration. This choice is justified by the simplicity of the design, both the active element and its drive.

Each point of the blade of the knife must have a peripheral speed $\omega$, providing an unsupported cut of plants in order to ensure high-quality work of the cutting apparatus. Figure $2[13 ; 14 ; 16]$ presents a kinematic diagram of operation of a segment-disc cutting unit.

The trajectory of any point of the segment of the cutting apparatus presents a trochoid, the field area cut by each segment is limited by two curves, one of which is the base trajectory with the radius $r_{0}$ (point $\mathrm{A}$ ) and the other with the tip of the segment cutting edge $\mathrm{c}$ with the radius $r_{1}$ (point $\mathrm{B}$ ). The trajectories of adjacent segments are displaced in the direction of the forward speed of the machine $V_{\mathrm{M}}$ by the distance $O O_{1}$, passed during the rotation of the cutting disk by an angle $\varphi=2 \pi / z_{n}$, where $z_{n}$ is the number of knives on the cutting rotor. 
Since the main problem with cutting a plant can occur in the rotary cutting unit when cutting with a knife base point $A_{2}$ (Fig. 3), which has a minimum absolute speed $V_{A \min }=\omega \cdot r_{0}-V_{M}$, determination of the diameter of the cutting disk is selected based on the condition of a reliable cut.

$$
V_{\text {Amin }}=\omega r_{0}-V_{M} \geq V_{p},
$$

where $V_{\mathrm{p}}$ - knife cutting speed, $\mathrm{m} \cdot \mathrm{s}^{-1}$.

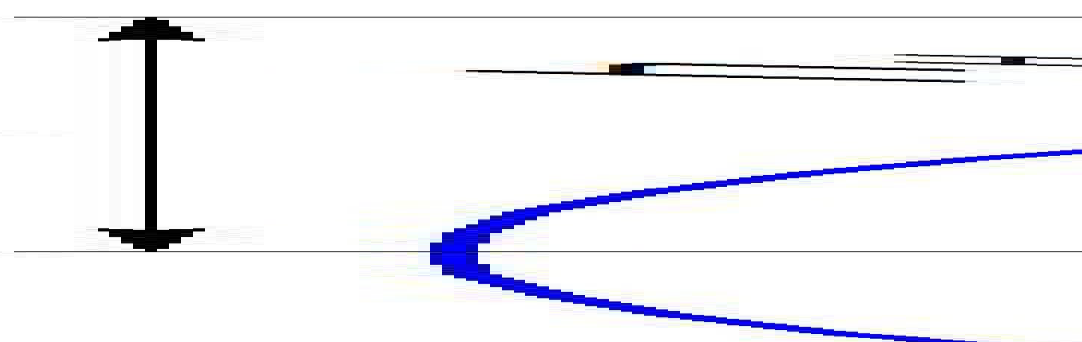

Fig. 2. Kinematic diagram of operation of segment-disc cutting unit

The technique outlined in the book of Dolgov I. A. [13] is used to determine the circumferential speed of the base of the cutting edge $U_{H}=\omega \cdot r_{0}$, which provides a reliable cut of plants. After transformation (1), the condition is obtained that must be satisfied by the radius of the disk.

$$
r_{0} \geq \frac{V_{p}+V_{u}}{\omega}, \mathrm{m} .
$$

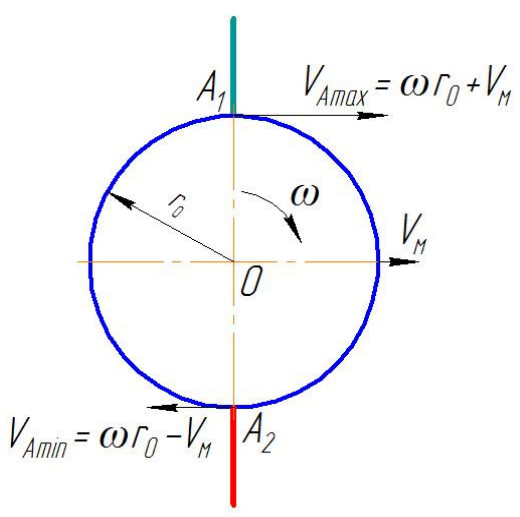

Fig. 3. Scheme for determining absolute speed of base of knife of segment-disk cutting apparatus

In the work [13], the author points out that a reliable non-supporting cut of plants begins to be provided at a knife speed of $V_{\mathrm{p}}=6-10 \mathrm{~m} \cdot \mathrm{s}^{-1}$.

Since the potato tops in the development phase, in which decapitation is supposed to be carried out, have a high humidity and a delicate fragile structure, the cutting speed is sufficient for the knife no more than $15 \mathrm{~m} \cdot \mathrm{s}^{-1}$.

For high-quality cutting of plants and elimination of blemishes during operation of the cutting apparatus, it is necessary that the stem deviation by the base of the cutting disc is absent. To do this, the condition (3) must be met, in which the trajectory of the apex of each subsequent blade, Fig. 2, when rotating the cutting disk, partially overlaps the path described by the base of the previous blade [14].

$$
O B_{1} \geq O C_{1}
$$


This condition is ensured by maintaining a certain ratio of the peripheral speed of the knife $U_{\mathrm{H}}$ and the speed of the movement of the unit $V_{\mathrm{M}}$, estimated by the kinematic mode indicator $\lambda=U_{H} / V_{M}$.

Figure 2 is considered to determine the index $\lambda$, which ensures that the condition (3) is met. Since $O B_{1}=x_{\mathrm{B} 1}$ and $O C_{1}=x_{\mathrm{C} 1}$ on it, the operating condition of the cutting unit will be written as follows

$$
x_{\mathrm{B} 1} \geq x_{\mathrm{C} 1}
$$

The values of $x_{\mathrm{B} 1}$ and $x_{\mathrm{C} 1}$ are determined depending on the kinematic regime $\lambda, r_{1}, r_{0}$ and the number of knives $z_{n}$ :

$$
\begin{gathered}
x_{B 1}=r_{0}\left(\frac{\pi}{2 \lambda}+\frac{r_{1}}{r_{0}}\right), \\
x_{C 1}=r_{0}\left[\frac{\pi\left(z_{n}+4\right)}{2 \lambda z_{n}}+1\right] .
\end{gathered}
$$

Transforming inequality (4), taking into account the values (5) and (6), is obtained by the following expression for determining the index of the kinematic mode depending on the parameters of the cutting unit

$$
\lambda \geq \frac{2 \pi r_{0}}{z_{n} h_{n}} .
$$

Since the adopted base speed of the blades of the knife is $U_{H}=V_{p}+V_{M}$, expression (7) is transformed and the formula is obtained for determining the total length of the cutting edges of the blades $z_{n} h_{n}$ :

$$
z_{H} h_{H} \geq \frac{2 \pi r_{0} V_{M}}{V_{p}+V_{M}} .
$$

From the obtained dependence it follows that the total length of the cutting edges of the rotor depends on its minimum radius, cutting speed $V_{\mathrm{p}}$ and machine speed $V_{\mathrm{M}}$.

Taking into account the expression (4), the obtained dependence (8) for the length of the cutting edge of the knife can be written as

$$
h_{n} \geq \frac{2 \pi V_{u}}{\omega z_{n}}, \text { or } h_{n} \geq \frac{60 V_{u}}{n z_{n}}, \mathrm{~m},
$$

where $\omega=\pi \cdot n / 30-$ rotor angular speed, $\mathrm{c}^{-1}$;

$n$-rotor speed, $\min ^{-1}$.

Decapitation is performed while the tractor is moving; when the reception is performed, the speed of the aggregate is on average $2 \mathrm{~m} \cdot \mathrm{s}^{-1}$.

A graph is proposed presented in Figure 4 to determine the two unknowns of expression (9)

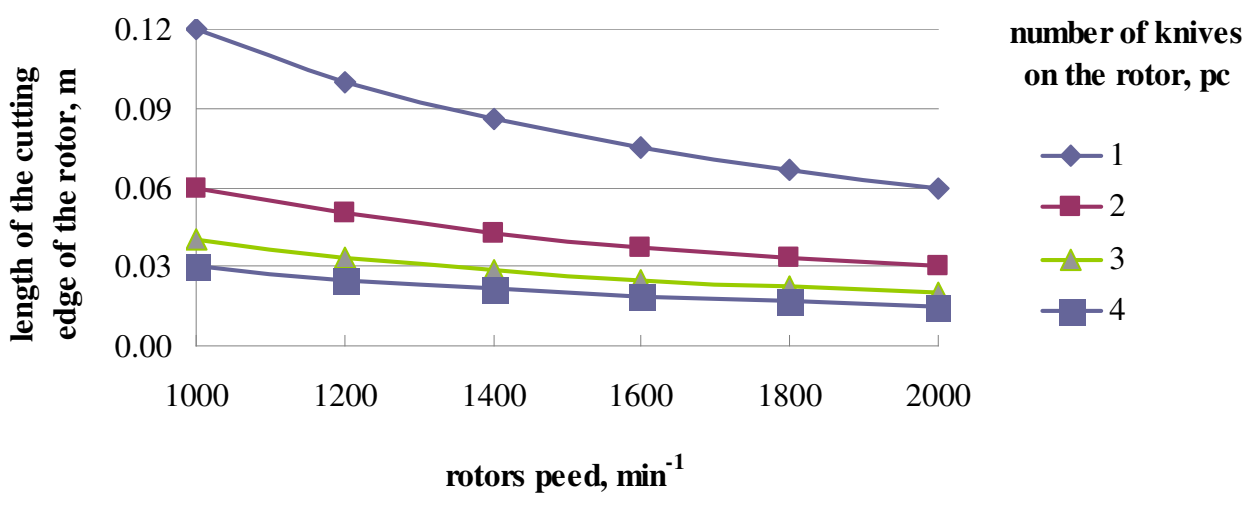

Fig. 4. Change in length of cutting edge of rotor depending on frequency of rotation of rotor and number of knives $\left(V_{M}=2 \mathrm{~m} \cdot \mathrm{s}^{-1}\right)$ 
Taking into account the data obtained, expressions (2) and the dependence of the outer radius of the rotor on the length of the cutting edge and the radius of the disc, the outer diameter of the blades for different rotor speed and the speed of the unit $2 \mathrm{~m} \cdot \mathrm{s}^{-1}$ are presented in the table.

Table 1

Values of the parameters of the cutting apparatus

\begin{tabular}{|c|c|c|c|c|c|c|c|}
\hline \multicolumn{2}{|c|}{ Rotor speed $\boldsymbol{n}, \mathbf{~ m i n}^{-1}$} & 1000 & 1200 & 1400 & 1600 & 1800 & 2000 \\
\hline \multicolumn{2}{|c|}{ Internal diameter, $\boldsymbol{d}_{\mathbf{0}}, \mathbf{m}$} & 0.32 & 0.27 & 0.23 & 0.20 & 0.18 & 0.16 \\
\hline \multirow{3}{*}{$\begin{array}{c}\text { External diameter } \boldsymbol{d}_{\mathbf{1}}, \text { by } \\
\text { number of cutting edges } \boldsymbol{z}_{\mathrm{H}}, \mathbf{m}\end{array}$} & $z_{\mathrm{H}}=1$ & 0.56 & 0.47 & 0.40 & 0.35 & 0.31 & 0.28 \\
\cline { 2 - 8 } & $z_{\mathrm{H}}=2$ & 0.44 & 0.37 & 0.32 & 0.28 & 0.25 & 0.22 \\
\cline { 2 - 8 } & $z_{\mathrm{H}}=3$ & 0.40 & 0.34 & 0.29 & 0.25 & 0.22 & 0.20 \\
\cline { 2 - 8 } & $z_{\mathrm{H}}=4$ & 0.38 & 0.32 & 0.27 & 0.24 & 0.21 & 0.19 \\
\hline
\end{tabular}

Based on the data in the table, it follows that with an increase in the number of the cutting blades, the intensity of changes in the size of the external diameter of the rotor decreases. Thus, with an increase in the number of the cutting edges from one to two, the external diameter of the knife will decrease by $21.3 \%$, from two to three - by $9 \%$, from three to four - by $5 \%$. Thus, it can be said that an increase in the number of knives on the rotor over three is impractical.

Reducing the number of knives leads to an increase in the length of each of them, which in turn will adversely affect operation of the disinfecting system, since in this case, to process the required length of the knife, the working nozzle will need to be removed from the rotor, which will lead to the loss of the power of the spray pattern.

Plants of different varieties of potatoes were examined and it was determined that in the period of $2-4$ weeks after germination, when decapitation is supposed to be performed, the diameter of the bush of the plants is within $0.25 \mathrm{~m}[1 ; 15]$. At the same time, it is necessary to take into account the fact that, in accordance with the agrotechnical requirements for planting potatoes, the width of the main rows is allowed to deviate from the given values $- \pm 4 \mathrm{~cm}$, and for butt spacing $- \pm 5 \mathrm{~cm}$ [16]. Accordingly, the cutting width of the cutting apparatus of the device in question must be such as to ensure the cut of the plants and in the case of a row deviation within the specified limits, i.e. the external diameter of the rotor blades should be about $0.35 \mathrm{~m}$.

\section{Conclusion}

The data obtained allow to conclude that to ensure high-quality and reliable cutting of potato shoots during decapitation a cutting rotor with three knives should be used, rotating at a frequency of $1200 \mathrm{~min}^{-1}$, having an external diameter of the cutting edges of at least $0.35 \mathrm{~m}$ blade $h_{\mathrm{H}}$, with the specified rotor parameters, will be about $0.04 \mathrm{~m}$.

\section{References}

[1] Shpaar D. Kartofel / D. Shpaar, V.Ivanyuk, P. Shumann, A. Postnikov [et al.]. Pod red. D. Shpaar. -Minsk: «FUAinform», 1999, $272 \mathrm{p}$.

[2] Nichiporovich A. A. Physiology of photosynthesis / A.A. Nichiporovich. - Moscow: Science, 1982, pp. 7-33.

[3] Botger M. Apical dominance in roots of Pisum sativum L. Planta, 12, 1970, pp. 253-261.

[4] Derfling K. Plant hormones: a systematic approach / K. Derfling; Per s nem. N.S Gel'man. - M.: Mir, 1985, $303 \mathrm{p}$.

[5] Atabekova A. I., Ustinova E. I. Plant Cytology, 4th ed. M.: Agropromizdat, 1980, 246 p.

[6] Lortic C.J, Aarssen L. W. Apical dominance as an adaptation in Verbassum Thapsus: effects of water and nutrients no branching. Jnt J Plant Sci. 158 (4), 1997, pp. 461-464.

[7] Mason M.G., Ross J.J., Babst B.A., Wienclaw B. N., Beverdge C. A. Sugar demand, not ausin is the initial regulator of apical dominance. Proc Nat Acad Sci. USA. 111(16), 2014, pp. 6092-6097.

[8] Hamann V. Intensivvermehrung der Kartoffel in der Stufe der Erhieltungszucht.- Ziemiak, Poznan, 1975, pp. 107-126.

[9] Shmyglya V. A. On the forms of existence of plant viruses // Bulletin of agricultural science, 1985. - № 2, 1985, pp. 100-103. 
[10] Kutsamanova I. N., Popkova K. V Methods of improvement of potatoes from viral diseases / / Proceedings of the scientific conference of young scientists and specialists. - Moscow: Publishing house of ICCA, 1999, pp. 49-54.

[11] Gasparyan I.N., Bicoev B.A. The device for decapitation of potatoes. Utility model patent. RUS 156015 from 03.07.2015.

[12] Gasparyan I.N., Levshin A.G. Theory and practice of increasing potato productivity using decapitation in the non-Chernozem zone of the Russian Federation: monograph / Irkutsk: LLC «Megaprint», 2017, $236 \mathrm{p}$.

[13] Dolgov I. A. Harvesting agricultural machines. (Construction, theory, calculation): Textbook. / I. A. Debt - Rostov n/D: Publishing center DGTU, 2003, 707 p.

[14] Klenin N. I. Agricultural and reclamation machines / N. I. Klenin, V. A. Sakun. - Moscow: Kolos, 1994, $751 \mathrm{p}$.

[15] Pisarev B.A. Production of early potatoes. - M.: Rosselkhoznadzor. - 1986, 287 p.

[16] Klenin N.I., Kiselev S.N., Levshin A.G. Agricultural vehicles. - M.: Koloss, 2008, 816 p. 